\title{
TRATAMENTOS PRÉ-GERMINATIVOS EM SEMENTES DE Samanea tubulosa Bentham - (Leguminoseae- Mimosoideae $)^{1}$
}

\author{
Lucicléia Mendes de Oliveira², Riselane de Lucena Alcântara Bruno³, Edna Ursulino Alves³, Danielle
}

Marie Macedo Sousa ${ }^{4}$ e Albericio Pereira de Andrade ${ }^{3}$

\begin{abstract}
RESUMO - Samanea tubulosa (Bentham) é uma árvore de grande porte, com fruto de sabor adocicado o que a privilegia como potencial apícola - contendo de 5 a 31 sementes, que apresentam dormência devido à impermeabilidade do tegumento. Dessa forma, objetivando selecionar métodos que proporcionem a superação dessa dormência, esta pesquisa foi realizada em laboratório e em ambiente telado, sem controle das condições ambientais, do Centro de Ciências Agrárias (CCA) da Universidade Federal da Paraíba. Os tratamentos utilizados foram: $\mathrm{T}_{1}$ controle; $\mathrm{T}_{2}$ desponte $\mathrm{T}_{3}, \mathrm{~T}_{4}$ e $\mathrm{T}_{5}$ imersão em ácido sulfúrico concentrado durante 5,10 e $15 \mathrm{~min}$, respectivamente; $\mathrm{e}_{6}, \mathrm{~T}_{7}, \mathrm{~T}_{8:}$ imersão em água quente por $1 \mathrm{~min}$, nas temperaturas de $60,70 \mathrm{e} 80^{\circ} \mathrm{C}$, respectivamente. Os parâmetros avaliados foram porcentagem de emergência, índice de velocidade de emergência (IVE) e comprimento e massa seca de plântulas. Com base nos resultados, os tratamentos que se destacaram na superação da dormência das sementes de Samanea tubulosa (Bentham) foram a escarificação ácida (ácido sulfúrico concentrado durante 5,10 e $15 \mathrm{~min}$ ) e o desponte, os quais foram responsáveis pelos melhores resultados de qualidade fisiológica das plântulas. Contudo, na prática, recomenda-se a utilização da escarificação com ácido sulfúrico concentrado durante 5 min ou, mesmo, do desponte.
\end{abstract}

Palavras-chave: Bordão-de-velho, Dormência, Emergência e Impermeabilidade.

\section{DORMANCY BREAK IN SEEDS OF SamaneatubulosaBenthan - (Leguminoseae- Mimosoideae)}

\begin{abstract}
Samaneatubulosa (Bentham) is a large tree with fruit of sweetened flavor-which potentiates the tree for apiculture use - containing from 5 to 31 seeds presenting dormancy due to the impermeability of its tegument. Thus, the objective of this work was to select methods to break dormancy of the seeds. The study was carried out in a laboratory and in a greenhouse environment, without control of environmental conditions at Centro de Ciências Agrárias (CCA) at Universidade Federal da Paraíba. The treatments used were the following: T1 - control; T2 - blunts; T3, T4 and T5 -immersion in concentrated sulfuric acid for 5, 10 and 15 minutes; and T6, T7, T8 - immersion in hot water for one minute at 60,70 and $80^{\circ} \mathrm{C}$, respectively. The parameters evaluated were the percentage of emergence, emergency velocity indices (IVE), length and dry weight of seedlings. The results showed that the treatments which stood out in dormancy break of seeds were acid scarification (concentrated sulfuric acid for 5, 10 and 15 minutes) and lopping, which accounted for the best results of physiological quality of seedlings. However, in practical terms, it is recommended the use of scarification with concentrated sulfuric acid for 5 minutes or even the lopping.
\end{abstract}

Keywords: Bordão de velho, Dormancy, Emergency and Impermeability.

\footnotetext{
${ }^{1}$ Recebido em 05.05.2009 e aceito para publicação em 19.04.2012

${ }^{2}$ Estudante de Pós Graduação em Ciência e Tecnologia de Sementes pela Universidade Federal de Pelotas, UFPEL, Brasil. E-mail: <lucicleia@biologa.bio.br>.

${ }^{3}$ Universidade Federal da Paraíba, UFPB, Brasil.E-mail <riselane@ pq.cnpq.br>,<ednaursulino@cca.ufpb.br>e <albericio@uol.com.br>.

${ }^{4}$ Universidade Federal de Campina Grande. E-mail <daniellemariem@yahoo.com.br>
} 


\section{INTRODUÇÃO}

A germinação representa a retomada do crescimento do embrião interrompido na fase de maturação da semente, e o processo germinativo também pode ser influenciado por fatores como longevidade, viabilidade, características genéticas da planta progenitora, condições climáticas durante a maturação, grau de injúria mecânica e condições de armazenamento, bem como temperatura, oxigênio e disponibilidade de água (CARVALHO; NAKAGAWA, 2000). Porém, as sementes dormentes, mesmo com todas as condições ambientais favoráveis, não conseguem germinar (FOWLER; BIACHETTI, 2000).

A dormência geralmente se mostra vantajosa para a sobrevivência das espécies em condições naturais, já que distribui a germinação ao longo do tempo ou permite que a germinação ocorra em condições favoráveis à sobrevivência das plântulas. No entanto, a dormência é, frequentemente, prejudicial às atividades de viveiro onde se deseja que as sementes germinem rapidamente, contribuindo para a produção de mudas uniformes (MEDEIROS FILHO et al., 2002). Portanto, o conhecimento das causas da dormência é de extrema importância para se obter o máximo de germinação. Entre as principais causas da dormência das sementes, destacam-se tegumento impermeável, embrião fisiologicamente imaturo ou rudimentar, substâncias inibidoras e embrião dormente. Dessa forma, depois de identificada a causa da dormência, diversos métodos podem ser empregados para superá-la, como a escarificação química e, ou, mecânica, o choque térmico, a água quente, entre outros (VIEIRA; FERNANDES, 1997).

A impermeabilidade do tegumento à água está associada a várias espécies vegetais de famílias botânicas conhecidas, como Leguminoseae, Malvaceae, Geraniaceae, Chenopodiaceae, Convolvulaceae, Solanaceae e Liliaceae, sendo essa causa de dormência encontrada especialmente na família Leguminoseae. A dureza do tegumento está relacionada à presença de substâncias impermeáveis à água, a exemplo de suberina, lignina, tanino, pectina e derivados de quinona, as quais impedem a germinação das sementes (CARVALHO; NAKAGAWA, 2000).

Nesse sentido, várias pesquisas foram realizadas com sementes de espécies florestais para aliviar a dormência. Por exemplo, na escarificação ácida (ácido sulfúrico) em Bowdichia virgiloides Kunton o melhor tratamento foi a imersão durante 5 min (SMIDERLE e SOUSA, 2003); em Albizia hassleri (Chodat) Bukarta, imersão de 1 a 3 min (FOWLER et al., 2006); em Caesalpinea ferrea Mart. ex Tu. var. leiostachya Benth., entre 19 e 25 min; em Ziziphus joazeiro Mart., na faixa de 74 a 115 min (ALVES et al., 2006); enquanto em Mimosa caesalpinia folia Benth, no período de 10 ou 13 min; e o desponte (BRUNO et al., 2001), no tempo de 10 a 15 min, segundo Garcia et al. (2002). Já em Bauhiniadivaricata o tratamento desponte foi o mais eficaz (ALVES et al., 2004). Portanto, deduz-se que o nível de dormência na semente varia entre as espécies, conforme a espessura do tegumento e também devido à presença de substâncias impermeáveis.

Os tratamentos à base de água quente também promoveram bons resultados, a exemplo da imersão em água a $100{ }^{\circ} \mathrm{C}$ por 1 min em sementes de Acacia mangium (SMIDERLE et al., 2005) e imersão das sementes de Peltophorum dubium em água a $95^{\circ} \mathrm{C}$, seguidas de repouso na mesma água por $24 \mathrm{~h}$, sem o aquecimento (OLIVEIRA et al., 2003). Enquanto em Albizia hassleri a imersão em água a 65, 70, 75, 80, 90 e $100{ }^{\circ} \mathrm{C}$ por $1 \mathrm{~min}$ promoveu a germinação das sementes com valores inferiores a 50\% (FOWLER et al., 2006). No entanto, não ocorreu germinação das sementes de Manihot glaziovii quando imersas em água a 80,90 e $100{ }^{\circ} \mathrm{C}$ por $2 \mathrm{~min}$ (RODOLFO JUNIOR et al., 2009).

Samanea tubulosa (Bentham) é uma árvore de grande porte, podendo atingir até $28 \mathrm{~m}$ de altura. Seu fruto é do tipo legume séssil indeiscente contendo de 5 a 31 sementes, carnoso, com polpa doce e perfumada. A emergência inicia-se de 14 a 42 dias após a semeadura para sementes com superação da dormência e de 40 a 90 dias sem tratamento pré-germinativo. Ocorre naturalmente nos biomas Amazônia, Caatinga, Pantanal, em capoeiras e áreas abertas, sendo encontrada, especialmente, em solos arenosos e bem drenados. É popularmente conhecida por samaneiro, sete-cascas, barba-de-velho, bordão-de-velho, farinha-seca, feijãocru, ingá-de-pobre, pau-de-cangaia e sete cascas (CARVALHO, 2007).

Como a maioria das plantas da família Leguminosae, esta também apresenta dormência em suas sementes devido à impermeabilidade do tegumento. Dessa forma, este trabalho teve como objetivo determinar os métodos que proporcionem a superação da dormência das sementes de Samanea tubulosa (Bentham). 


\section{MATERIAL E MÉTODOS}

O experimento foi realizado em ambiente telado, sem controle das condições ambientais, no Departamento de Fitotecnia e Ciências Ambientais do Centro de Ciências Agrárias (CCA) da Universidade Federal da Paraíba (UFPB), Campus II, em Areia, PB. Partiu-se de 10 matrizes de Samanea tubulosa (Bentham), nas quais foram coletados 500 frutos maduros, numa altura de aproximadamente $15 \mathrm{~m}$, contendo em média 25 sementes por fruto, as quais foram enviadas ao laboratório para beneficiamento e, em seguida, dar início ao experimento.

As sementes foram submetidas a tratamentos para superar a dormência, tomando-se como testemunha (sementes sem tratamento $-\mathrm{T}_{1}$ ). Para obter mais rapidez e uniformidade na emergência das plântulas, as sementes foram submetidas ao desponte com tesoura na região oposta ao hilo - $\left(\mathrm{T}_{2}\right)$, imersão em ácido sulfúrico (98\%) durante 5,10 e $15 \min \left(\mathrm{T}_{3}, \mathrm{~T}_{4}\right.$ e $\mathrm{T}_{5}$, respectivamente), sendo após esse período lavadas em água corrente para a retirada do resíduo do ácido durante $10 \mathrm{~min}$. Quanto aos tratamentos com água quente, as sementes foram imersas por $1 \mathrm{~min}$, nas temperaturas de 60, 70, 80,90 e $100{ }^{\circ} \mathrm{C}\left(\mathrm{T}_{6}, \mathrm{~T}_{7}, \mathrm{~T}_{8}, \mathrm{~T}_{9}\right.$ e $\mathrm{T}_{10}$, respectivamente $)$.

Depois de submetidas aos tratamentos, as sementes foram semeadas a uma profundidade de $1,0 \mathrm{~cm}$, em bandejas plásticas perfuradas no fundo, contendo areia lavada e esterilizada em autoclave, umedecida com quantidade de água equivalente a $60 \%$ da capacidade de retenção, cuja manutenção da umidade foi mantida por meio de irrigações diárias matinais, permanecendo em ambiente telado, onde se avaliaram as seguintes características:

Emergência - Foram utilizadas 100 sementes por tratamento, divididas em quatro subamostras de 25. A contagem foi realizada aos 15 dias após a semeadura, quando houve a estabilização da emergência das plântulas. Adotou-se o critério de plântulas normais, conforme indicado por Brasil (1992), com os resultados expressos em porcentagem.

Índice de Velocidade de Emergência (IVE) - Foi determinado mediante a contagem diária de plântulas que apresentavam cotilédones acima do substrato, a partir do terceiro dia, e finalizando com a estabilização da emergência. Esse índice foi calculado apor meio da fórmula proposta por Maguire (1962).

Comprimento total de plântulas - No final do teste de emergência, as plântulas normais de cada repetição foram medidas com régua graduada em centímetros, desde a coifa até o meristema apical, cujos resultados foram expressos em centímetros por plântula.

Massa seca de plântulas - Depois de medidas, as plântulas foram colocadas em estufa com circulação de ar regulada para $65^{\circ} \mathrm{C}$ até atingir peso constante. Decorrido esse período, foram colocadas em dessecadores e, em seguida, pesadas em balança analítica com precisão de $0,001 \mathrm{~g}$, sendo os dados expressos em g/plântula.

Todas as características estudadas das plântulas de Samanea tubulosa (Bentham) exibiram efeito significativo após os tratamentos das sementes com métodos para superação da dormência, conforme os resultados apresentados no resumo da análise de variância (Tabela 1). Entretanto, os tratamentos $\mathrm{T}_{9}$ e $\mathrm{T}_{10}$, respectivamente imersão em água a 90 e $100^{\circ} \mathrm{C}$ por $1 \mathrm{~min}$, podem ter provocado dano aos embriões a ponto de lhes causarem a morte, pois nenhuma plântula emergiu. Dessa forma, optou-se por não submetê-los à análise estatística. Resultados semelhantes foram obtidos por Rodolfo Junior et al. (2009), em sementes de Manihot glaziovii.

O delineamento utilizado foi inteiramente casualizado com oito tratamentos e quatro repetições de 25 sementes. Os dados foram submetidos à análise de variância pelo teste $\mathrm{F}$ e as médias, comparadas pelo teste de Tukey a $5 \%$ de probabilidade, por meio do programa SAEG versão 9.1/2007.

\section{RESULTADOS E DISCUSSÃO}

Observou-se que a emergência das plântulas de S. tubulosa iniciou aos três dias após a semeadura das sementes previamente tratadas. Fato semelhante foi constatado nas descrições realizadas por Carvalho (2007) também da mesma espécie, porém a dormência só foi superada no décimo quarto dia de semeio, quando mantidas sob as condições ambientais do Estado da Bahia. Também cabe ressaltar que as sementes que não receberam nenhum tratamento (testemunha) somente começaram a germinar e, assim, emitir plântulas aos 10 dias do semeio.

De acordo com os dados da Figura 1, observa-se que os tratamentos $\mathrm{T}_{3}$ e $\mathrm{T}_{5}$ (imersão em ácido sulfúrico concentrado por 5 e $15 \mathrm{~min}$ ) não apresentaram diferença significativa entre si e foram responsáveis pelos maiores

Revista Árvore, Viçosa-MG, v.36, n.3, p.433-440, 2012 
percentuais de emergência de plântulas, com valores superiores a $70 \%$, em comparação com os da testemunha $\left(\mathrm{T}_{1}\right)$, que mostrou emergência de $17 \%$. É válido ressaltar também que os tratamentos $\mathrm{T}_{3}$ e $\mathrm{T}_{5}$ não diferiram de $\mathrm{T}_{2}$ (desponte na região oposta ao hilo), $\mathrm{T}_{4}$ (imersão em ácido sulfúrico concentrado por $10 \mathrm{~min}$ ) e $\mathrm{T}_{7}$ (imersão das sementes em água quente a $70^{\circ} \mathrm{C}$ por $1 \mathrm{~min}$ ). Já na maioria dos tratamentos com água quente ocorreu porcentagem de germinação muito baixa em comparação com os tratamentos de escarificação ácida e desponte, necessitando, portanto, de mais estudos com relação ao tempo de imersão combinado com as respectivas temperaturas, para que dessa forma se possa obter o binômio tempo-temperatura ideal.

Tabela 1 - Resumo da análise de variância das características avaliadas das plântulas de Samanea tubulosa: Emergência (EMER \%), Índice de Velocidade de Emergência (IVE), Comprimento de Plântulas (COMP) e Massa Seca de Plântulas (MASS). Areia, PB, 2009.

Table 1 - Summary of the analysis of variance of the assessed characteristics of the seedlings of Samanea tubulosa: Emergency (EMER \%), Index of Emergency Speed (IVE), Length of the Seedlings (COMP) and Dry Mass of Seedlings (MASS). Areia, PB, 2009.

\begin{tabular}{lccccc}
\hline & \multicolumn{3}{c}{ Quadrados médios } \\
\hline FV & GL & EMER & IVE & COMP & $0,3105067 \mathrm{E}-02^{*}$ \\
\cline { 2 - 6 } Tratamentos & 7 & $1630,857^{*}$ & $14,65541^{*}$ & $27,86479 *$ & 1,209494 \\
Resíduo & 24 & 121,5000 & 1,472603 & & \\
Total & 31 & & & 14,11125 & 0,07984 \\
Média & & 48,75000 & 2,97594 & 7,794 & 8,381 \\
\hline CV(\%) & & 22,611 & 40,777 & & \\
\hline
\end{tabular}

*Significativo a $1 \%$ de probabilidade.

$\mathrm{CV}=$ coeficiente de variação.

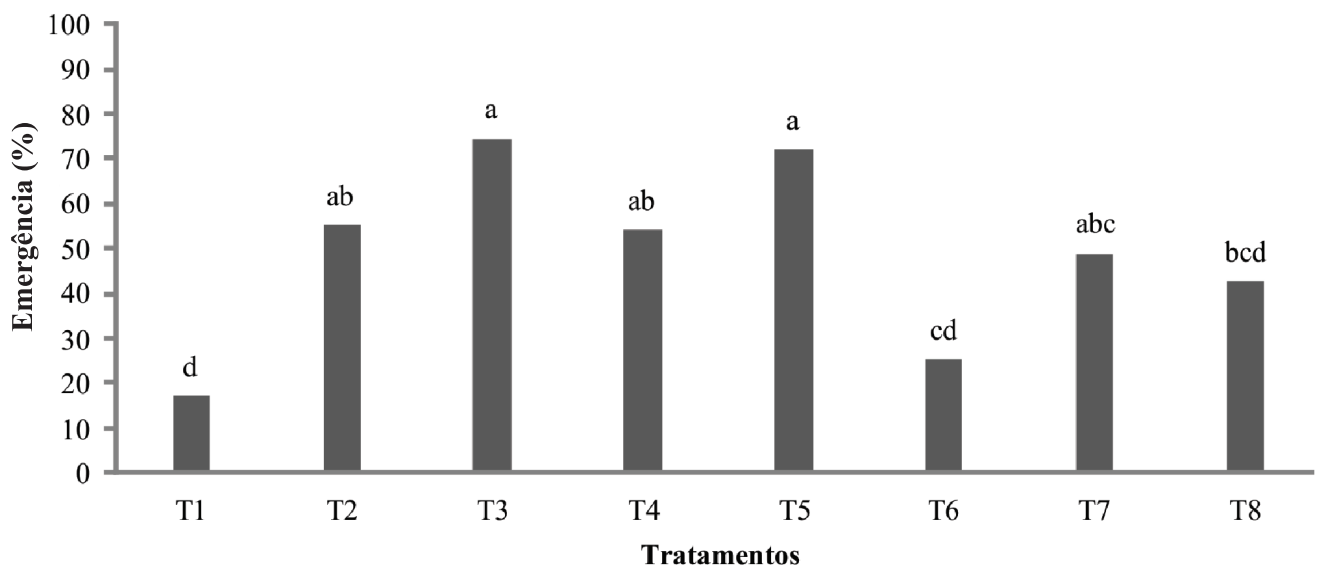

Figura 1 - Porcentagem média da emergência (\%) de plântulas de Samanea tubulosa (Bentham) oriundas de sementes submetidas a diferentes tratamentos para superar a dormência. Tratamentos: testemunha $\left(\mathrm{T}_{1}\right)$; desponte na região oposta ao hilo $\left(\mathrm{T}_{2}\right)$; imersão em ácido sulfúrico concentrado durante 5,10 e $15 \mathrm{~min}\left(\mathrm{~T}_{3}, \mathrm{~T}_{4}\right.$ e $\left.\mathrm{T}_{5}\right)$, seguida de lavagem em água corrente por $10 \mathrm{~min}$; e imersão das sementes em água quente por $1 \mathrm{~min}$, nas temperaturas de 60,70 e $80{ }^{\circ} \mathrm{C}\left(\mathrm{T}_{6}, \mathrm{~T}_{7}\right.$ e $\left.\mathrm{T}_{8}\right)$.

Figure 1 - Average percentage of emergency of Samanea tubulosa (Bentham) seedlings from seeds submitted to different treatments to break dormancy. Treatments: control (T1); lopping in the region opposite the hilum (T2); immersion in concentrated sulfuric acid for 5, 10 and 15 minutes $\left(T_{3}, T_{4}\right.$ e $\left.T_{5}\right)$, followed by washing in running water for 10 minutes; and soaking seeds in hot water for one minute, at 60,70 and $80^{\circ} \mathrm{C}\left(T_{6} T_{7}\right.$ e $\left.T_{8}\right)$.

Revista Árvore, Viçosa-MG, v.36, n.3, p.433-440, 2012 
Apesar de não terem ocorrido diferenças significativas entre os tratamentos citados, verificou-se, assim, que a escarificação com $\mathrm{H}_{2} \mathrm{SO}_{4}$ foi mais eficiente em romper o tegumento das sementes de $S$. tubulosa, uma vez que acelerou o processo de embebição, culminando com a germinação e consequente emergência das plântulas. Resultados semelhantes foram obtidos em sementes de Bowdichia virgiloides Kunt por Smiderle e Sousa (2003), quando utilizaram o $\mathrm{H}_{2} \mathrm{SO}_{4}$ por 5 e $10 \mathrm{~min}$, proporcionando os percentuais de germinação de 90 e $51 \%$, respectivamente. Provavelmente os fatores determinantes da impermeabilidade do tegumento das sementes de S. tubulosa e Bowdichia virgiloides sejam semelhantes, já que o tempo de escarificação de ambas por 5 min no ácido foi suficiente para enfraquecer os tecidos.

Por meio do índice de velocidade de emergência (Figura 2), foi possível visualizar a eficiência do uso da imersão das sementes em ácido sulfúrico por 5, 10 e 15 min, respectivamente $\mathrm{T}_{3}, \mathrm{~T}_{4}$ e $\mathrm{T}_{5}$, em relação aos demais tratamentos, porém não diferindo estatisticamente de $\mathrm{T}_{2}$ (desponte). Analisando comparativamente os dados de emergência (Figura 1) e IVE (Figura 2), notou-se que os tratamentos à base de ácido e o desponte sobressaíram em relação aos demais, proporcionando, assim, maior velocidade de germinação das sementes. Dessa forma, constatou-se a eficácia desses métodos para tornar o tegumento das sementes mais permeável à entrada de água, com absorção imediata e, consequentemente, desencadeando o processo germinativo.

Fato similar ao deste estudo foi observado por Alves et al. (2004) em sementes de Bauhinia divaricata L., em que o desponte se destacou dos demais tratamentos, com o maior índice de velocidade de emergência. Hermansen et al. (2000) recomendaram a escarificação mecânica para a superação da dormência de Dimorphandra mollis por ser técnica frequentemente utilizada, dadas a sua praticidade e segurança para pequenos agricultores. Entretanto, Smiderle e Sousa (2003) também obtiveram os maiores índices de velocidade de emergência quando utilizaram as sementes de Bowdichia virgilioides Kunt em $\mathrm{H}_{2} \mathrm{SO}_{4}$ por 5 e $10 \mathrm{~min}$. Ainda em relação às sementes de $S$. tubulosa, constatou-se que os métodos menos eficientes foram imersão em água quente nas temperaturas de 60,70 e $80{ }^{\circ} \mathrm{C}\left(\mathrm{T}_{6}\right.$, $\mathrm{T}_{7} \mathrm{e}_{8}$, respectivamente), bem como a testemunha $\left(\mathrm{T}_{1}\right)$,

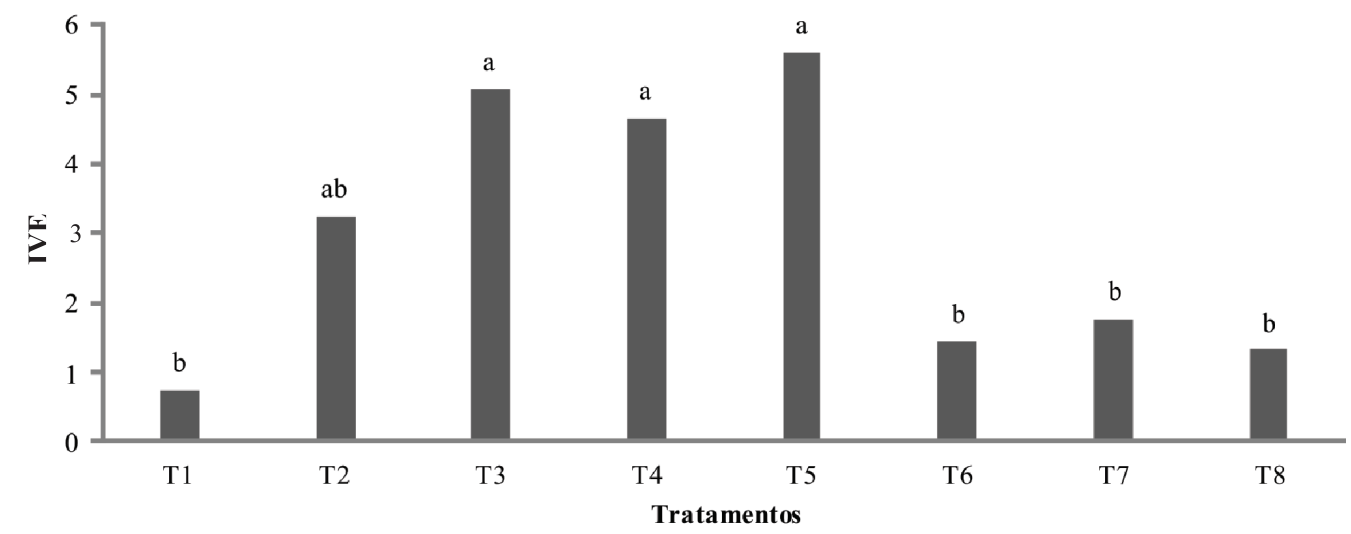

Figura 2 - Valores médios do Índice de Velocidade de Emergência (IVE) de plântulas de Samanea tubulosa (Bentham) oriundas de sementes submetidas a diferentes tratamentos para superar a dormência. Tratamentos: testemunha $\left(\mathrm{T}_{1}\right)$; desponte na região oposta ao hilo $\left(\mathrm{T}_{2}\right)$; imersão em ácido sulfúrico concentrado durante 5,10 e $15 \min \left(\mathrm{T}_{3}, \mathrm{~T}_{4} \mathrm{e}_{5}\right)$, seguida de lavagem em água corrente por $10 \mathrm{~min}$; e imersão das sementes em água quente por $1 \mathrm{~min}$, nas temperaturas de 60,70 e $80{ }^{\circ} \mathrm{C}\left(\mathrm{T}_{6}, \mathrm{~T}_{7}, \mathrm{~T}_{8}\right)$.

Figure 2-Mean values of emergency speed index (IVE) of Samanea tubulosa (Bentham) seedlings from seeds submitted to different treatments to break dormancy. Treatments: control (T1); lopping in the region opposite the hilum (T2); immersion in concentrated sulfuric acid for 5, 10 and 15 minutes $\left(T_{3}, T_{4}\right.$ e $\left.T_{5}\right)$, followed by washing in running water for 10 minutes; and soaking seeds in hot water for one minute, at 60,70 and $80{ }^{\circ} \mathrm{C}\left(T_{6}\right.$. $T_{7}$ e $T_{8}$ ). 


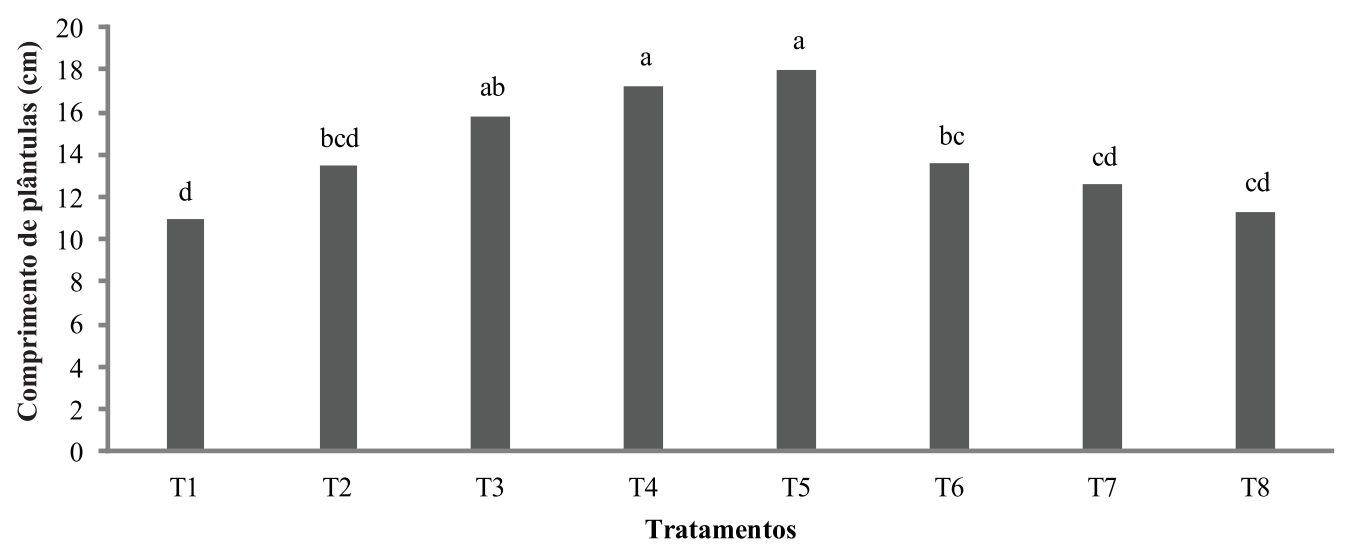

Figura 3 - Valores médios do comprimento total de plântulas (cm) de Samanea tubulosa (Bentham) oriundas de sementes submetidas a diferentes tratamentos para superar a dormência. Tratamentos: testemunha $\left(T_{1}\right)$; desponte na região oposta ao hilo $\left(\mathrm{T}_{2}\right)$; imersão em ácido sulfúrico concentrado durante 5,10 e $15 \mathrm{~min}\left(\mathrm{~T}_{3}, \mathrm{~T}_{4}\right.$ e $\left.\mathrm{T}_{5}\right)$, seguida de lavagem em água corrente por $10 \mathrm{~min}$; e imersão das sementes em água quente por $1 \mathrm{~min}$, nas temperaturas de 60,70 e $80{ }^{\circ} \mathrm{C}\left(\mathrm{T}_{6}, \mathrm{~T}_{7}\right.$ e $\left.\mathrm{T}_{8}\right)$.

Figure 3 - Mean values of total length of seedlings ( $\mathrm{cm}$ ) of Samanea tubulosa (Bentham) from seeds submitted to different treatments to break dormancy. Treatments: control (T1); lopping in the region opposite the hilum (T2); immersion in concentrated sulfuric acid for 5,10 and 15 minutes $\left(T_{3}, T_{4}\right.$ e $\left.T_{5}\right)$, followed by washing in running water for 10 minutes; and soaking seeds in hot water for one minute, at 60,70 and $80{ }^{\circ} \mathrm{C}\left(T_{6,} T_{7}\right.$ e $\left.T_{8}\right)$.

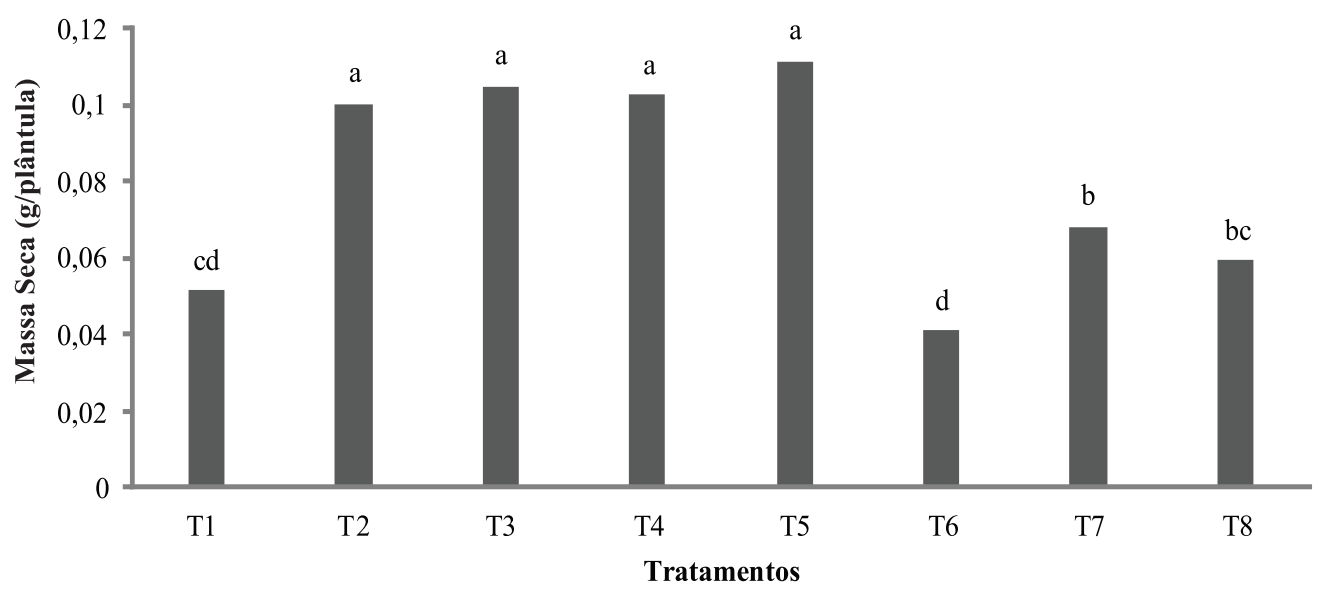

Figura 4 - Valores médios da massa seca total de plântulas de Samanea tubulosa (Bentham) oriundas de sementes submetidas a diferentes tratamentos para superar a dormência. Tratamentos: testemunha $\left(\mathrm{T}_{1}\right)$; desponte na região oposta ao hilo $\left(\mathrm{T}_{2}\right)$; imersão em ácido sulfúrico concentrado durante 5, 10 e $15 \mathrm{~min}\left(\mathrm{~T}_{3}, \mathrm{~T}_{4}\right.$ e $\left.\mathrm{T}_{5}\right)$, seguida de lavagem em água corrente por $10 \mathrm{~min}$; e imersão das sementes em água quente por $1 \mathrm{~min}$, nas temperaturas de 60 , 70 e $80{ }^{\circ} \mathrm{C}\left(\mathrm{T}_{6}, \mathrm{~T}_{7}, \mathrm{~T}_{8}\right)$.

Figure 4-Mean values of total dry mass of seedlings of Samanea tubulosa (Bentham) originated from seeds submitted to different treatments to break the dormancy. Treatments: control (T1); lopping in the region opposite the hilum (T2); immersion in concentrated sulfuric acid for 5,10 and 15 minutes $\left(T_{3}, T_{4}\right.$ e $\left.T_{5}\right)$, followed by washing in running water for 10 minutes; and soaking seeds in hot water for one minute, at 60, 70 and $80^{\circ} \mathrm{C}\left(T_{6} T_{7}\right.$ e $\left.T_{8}\right)$.

Revista Árvore, Viçosa-MG, v.36, n.3, p.433-440, 2012 
já que não apresentaram diferenças significativas e provavelmente o emprego do tratamento à base de água quente, assim como o tempo de imersão das sementes, não tenha sido suficiente para desencadear o processo germinativo de maneira uniforme. Dessa forma, os resultados da espécie em estudo não se mostraram eficazes na superação da dormência, fato também observado por Fowler et al. (2006) em sementes de Albizia hassleri (Chodat) Bukart.

Avaliando o desempenho das plântulas através do comprimento total, verificou-se que os maiores valores foram obtidos (entre 16 e $18 \mathrm{~cm}$ ) após a imersão das sementes em ácido sulfúrico por 5, 10 e 15 min $\left(\mathrm{T}_{3}, \mathrm{~T}_{4}\right.$ $\mathrm{e}_{5}$, respectivamente), novamente mostrando a eficiência desses tratamentos na superação da dormência. Resultados similares foram observados por Alves et al. (2009) em Caesalpinia ferrea, quando as sementes foram imersas por $19 \mathrm{~min}$, pois, de acordo com esses autores, o pressuposto básico para a superação da dormência não basta somente desencadear o processo germinativo, mas também o desempenho rápido e uniforme das plântulas. No entanto, Souza et al. (2008) destacaram que o uso de materiais abrasivos é eficiente para romper o tegumento espesso das sementes, mas podem-se obter bons resultados utilizando tratamentos de escarificação mecânica (lixa) e água quente.

Analisando a quantidade de massa seca armazenada nas plântulas (Figura 4), verificou-se mais uma vez que as maiores respostas foram obtidas quando se utilizou a superação da dormência das sementes pela escarificação ácida $\left(T_{3}, T_{4}\right.$ e $\left.T_{5}\right)$ e também através do desponte $\left(\mathrm{T}_{2}\right)$. Entretanto, ao considerar as outras variáveis (índice de velocidade de emergência, porcentagem de emergência e comprimento de plântulas), é possível inferir que o ácido sulfúrico atuou como agente escarificante, proporcionando, dessa forma, o maior enfraquecimento do tegumento e permitindo a emergência mais rápida. Fato semelhante foi observado por Bruno et al. (2001) ao estudarem o desempenho germinativo das sementes de Mimosa caesalpiniafolia Benth, sob duas classes de coloração, clara e escura, em que os maiores valores $(0,0053$ e 0,0057 g) de matéria seca foram obtidos nas sementes claras. Já o tratamento com água quente causou danos, uma vez que os referidos autores constataram os menores conteúdos de matéria seca, independentemente da coloração das sementes. Em Caesalpinia ferrea, Alves et al. (2009) também obtiveram os maiores acúmulos de massa seca das plântulas após as sementes terem sido pré-tratadas com ácido sulfúrico durante 24 min de imersão. Porém, se as sementes permanecessem imersas por períodos mais prolongados, isso afetava o seu desenvolvimento e, consequentemente, reduzia-lhe a quantidade de massa seca.

\section{CONCLUSÃO}

A utilização do ácido sulfúrico concentrado durante 5, 10 e 15 min e do desponte se mostrou eficaz na superação da dormência das sementes de Samanea tubulosa (Bentham) e foi responsável pelos maiores resultados da qualidade fisiológica das plântulas emersas. Porém, considerando a praticidade do processo, recomenda-se utilizar o menor tempo de escarificação ácida (5 min) ou, mesmo, o desponte.

\section{REFERÊNCIAS}

ALVES, E. U. et al. Ácido sulfúrico na superação da dormência de unidades de dispersão de juazeiro (Zizyphus joazeiro Mart.). Revista Árvore, v.30, n.2, p.187-195, 2006.

ALVES, A. U. et al. Superação da dormência em sementes de Bauhinia divaricata L. Acta Botânica Brasílica, v.18, n.4, p.871-879, 2004.

ALVES, E. A. et al. Escarificação ácida na superação da dormência de sementes de pau ferro (Caesalpinea ferrea Mart.ex Tu. var. leiostachya Benth.). Revista Caatinga, v.22, n.1, p.37-47, 2009.

BRASIL. Ministério da Agricultura e Reforma Agrária. Regras para análise de sementes. Brasília: SNA/DNDV/CLAV, 1992. 188p.

BRUNO, R. L. A. et al. Tratamentos prégerminativos para superar a dormência de sementes de Mimosa caesalpiniaefolia Benth.

Revista Brasileira de Sementes, v.23, n.2, p.136-143, 2001.

CARVAlho, N. M.; NAKAGAWA, J. Sementes: ciências tecnologia e produção. 4.ed. Jaboticabal: FUNEP, 2000.

CARVALHO. P. E. R. Bordão-de-Velho (Samanea tubulosa). Colombo: 2007. (Circular Técnica, 132).

Revista Árvore, Viçosa-MG, v.36, n.3, p.433-440, 2012 
FOWLER, J. A. P.; BIANCHETTI, A.

Dormência em sementes florestais. Colombo: Embrapa Florestas, 2000. 27p. (Embrapa Florestas. Documentos 40).

FOWLER, J. A. P.; CARPANEZZI, A. A.; ZUFFELLATO-RIBAS, K. C. Tecnologia para o Manejo Adequado de Sementes de Farinha-seca. Boletim de Pesquisa Florestal, n. 53, p. 195-208, 2006

GARCIA, J.; DUARTE, J. B.; FRASSETO, E. G. Superação de dormência em sementes de sansão-do-campo (Mimosa caesalpiniaefolia L.). Pesquisa Agropecuária Tropical, v.32, n. 1, p.29-31, 2002.

HERMANSEN, L. A. et al. Pretreatments to overcome seed coat dormancy in Dimorphandra mollis. Seed Science and Technology, v.28, n.1, p.581-595, 2000.

MAGUIRE, L. D. Speed of germination - aid in selection and evolution for seedling emergence and vigor. Crop Science, v.2, n.2, p.176-177, 1962.

MEDEIROS FILHO, S.; FRANÇA, E. A.; INNECCO, R. Germinação de sementes de Operculina macrocarpa (L.) Farwel e Operculina alata (Ham.) Urban. Revista Brasileira de Sementes, v.24, n.2, p.102-107, 2002.
OLIVEIRA, L. M.; DAVIDE, A. C.; CARVALHO, M. L. M. Avaliação de métodos para quebra da dormência e para a desinfestação de sementes de canafístula (Peltophorum dubium) [Sprengel] Taubert. Revista Árvore, v.27, n.5, p.597-603, 2003.

RODOLFO JUNIOR, F. et al. Tecnologia alternativa para a quebra de dormência de sementes de maniçoba (Manihot glaziovii, Euphorbiaceae). Revista Caatinga, v.22, n.1, p.20-26, 2009.

SMIDERLE, O. J.; SOUSA, R. C. P. Dormência em sementes de paricarana (Bowdichia virgiloides Kunt - Fabaceae - Papilionidae). Revista Brasileira de Sementes, v.25, n.2, p.48-58, 2003.

SMIDERLE,O. J.; MOURÃO JUNIOR, M.; SOUSA, R. C. P. Tratamentos pré-germinativos em sementes de acácia. Revista Brasileira de Sementes, v.27, n.1, p.78-85, 2005.

SOUZA, S. C. A. et al. Escarificação de sementes de Senna spectabilis (DC) Irwin et Barn. (Fabaceae - Caesalpinioideae). In: SIMPÓSIO NACIONAL DO CERRADO, 2., SIMPÓSIO INTERNACIONAL SAVANAS TROPICAIS, 9., 2008, Brasília. Anais... Brasília: ParlaMundi, 2008. p.1-7.

VIEIRA, I. G.; FERNADES, G. D. Métodos de quebra de dormência de sementes. Piracicaba: IPEF-LCF/ ESALQ/USP, 1997. (Informativo Sementes IPEF) Disponível em: <http://www.ipef.br/ sementes/>. Acesso em: 07 jun. de 2007. 